\title{
Erratum to: The antennal sensilla of Melipona quadrifasciata (Hymenoptera: Apidae: Meliponini): a study of different sexes and castes
}

Samira Veiga Ravaiano • Ríudo de Paiva Ferreira • Lucio Antonio de Oliveira Campos •

Gustavo Ferreira Martins

Published online: 2 July 2014

(C) Springer-Verlag Berlin Heidelberg 2014

Erratum to: Naturwissenschaften

DOI 10.1007/s00114-014-1184-0

The original publication of this article has incorrect presentation of Table 2. Correct table is shown on the following page.

The online version of the original article can be found at http://dx.doi.org/ 10.1007/s00114-014-1184-0.

S. V. Ravaiano · G. F. Martins

Departamento de Entomologia, Universidade Federal de Viçosa

(UFV), 36570-900 Viçosa, Minas Gerais, Brazil

R. d. P. Ferreira • L. A. d. O. Campos • G. F. Martins ( $₫)$

Departamento de Biologia Geral, Universidade Federal de Viçosa

(UFV), 36570-900 Viçosa, Minas Gerais, Brazil

e-mail: gmartins@ufv.br 


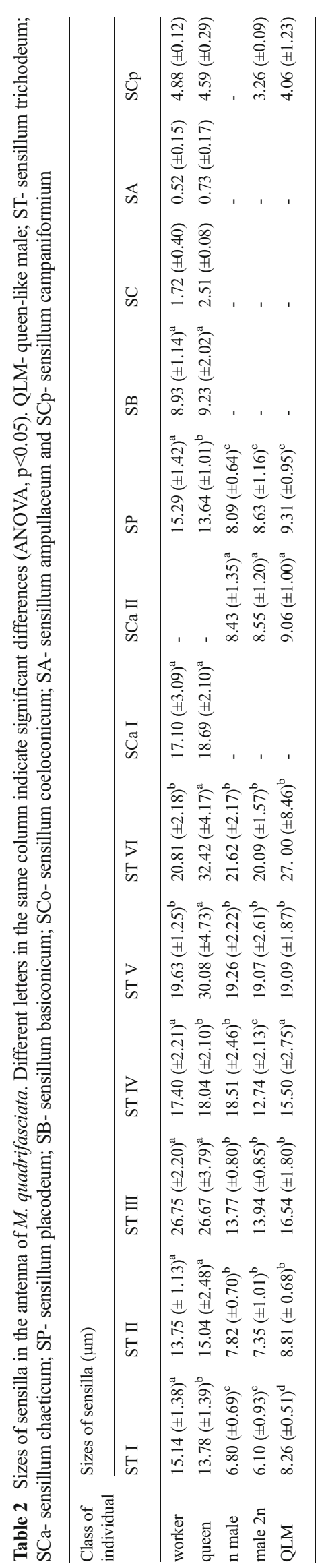

